\title{
AIR LEAK SYNDROME AND A RARE CASES PRESENTATION OF PNEUMOPERICARDIUM ASSOCIATED WITH AIR EMBOLISM IN TTN BABY
}

\author{
Dinakara Prithviraj ${ }^{1}$, Suresh A2 ${ }^{2}$ Anna Mariam Paul ${ }^{3}$
}

\section{HOW TO CITE THIS ARTICLE:}

Dinakara Prithviraj, Suresh A, Anna Mariam Paul. "Air Leak Syndrome and a Rare Cases Presentation of Pneumopericardium Associated with Air Embolism in TTN Baby". Journal of Evolution of Medical and Dental Sciences 2014; Vol. 3, Issue 15, April 14; Page: 3964-3969, DOI: 10.14260/jemds/2014/2384

ABSTRACT: Air leak syndromes are a group of clinically recognizable disorders produced by alveolar rupture and subsequent escape of air in to the tissue in which air is not normally present. All the clinical types of air leak syndrome originate in over distended alveoli, which ultimately rupture. Over distention is because of spontaneous vigorous respirations (usually larger term babies) at birth, increased pressure of mechanical ventilator (PEEP, PIP) vigorous Cardio Pulmonary resuscitation, air trapping in the presence of a ball valve mechanism, most of this air leaks occur spontaneously, but incidence increases with ventilator support, in some cases of collagen vascular diseases and associated renal problems. ${ }^{1}$ But in our study spontaneous pneumopericardium with air embolism a rare presentation and spontaneously recovered and followed up to one year. Timely radiological investigations including x-rays, USG chest, and ultra sound guided drainage of pneumopericardium with help of radiologist, play an important role in the management preventing morbidity and mortality.

KEYWORDS: TTN=Transient Tachypnea of Newborn, Pneumopericardium, systemic air embolism, MCA= Middle cerebral artery, Cyanosis, Respiratory distress.

INTRODUCTION: Neonatal pneumopericardium (PPC) is a frequently encountered complication of cardiopulmonary resuscitation and baby on ventilator care. However, the appropriate management remains controversial.

MATERIALS AND METHODS: Here we present a case of newborn with TTN with respiratory distress on evaluation was detected to have pneumopericardium. Prompt and timely intervention improved the outcome of the neonate.

CASE PRESENTATION: A twenty hours old female baby, delivered through LSCS (indication - failure to Progress).Baby cried immediately after birth needing only suction and stimulation at the time of birth. APGAR $1^{\text {st }}=8,5^{\text {th }}=9$.

Birth weight $=2.5 \mathrm{kgs}$. Mild indrawing, grunting and respiratory distress was noted and subsequently baby was admitted in NICU. Oxygen given by head box, IV fluids, empirical antibiotics. Chest X- ray revealed severe TTN. Gradually Respiratory Rate increased from 60 to $80 / \mathrm{min}$, indrawing and grunting persisted, needing increment of 02 from $3 \mathrm{~L}-5 \mathrm{~L} / \mathrm{min}$.

After twelve hours condition was same. Chest X-Ray (Fig: 1) showed same features suddenly SPO2 started fluctuating from $95 \%$ to $90-85 \%$ at nineteen hours of life. Repeat chest X-Ray revealed mild pneumopericardium and the patient was shifted to our NICU for further treatment (during nineteen hours to twenty hours of life SPO2 fluctuation increased). 


\section{CASE REPORT}

\section{PNEUMOPERICARDIUM WITH AIR EMBOLISM CASE REPORT PHOTOS:}

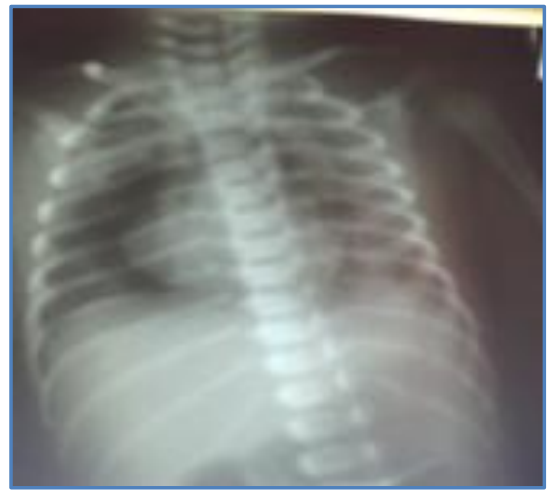

Fig. 1: CHEST X-RAY REVEALING PNEUMOPERICARDIUM

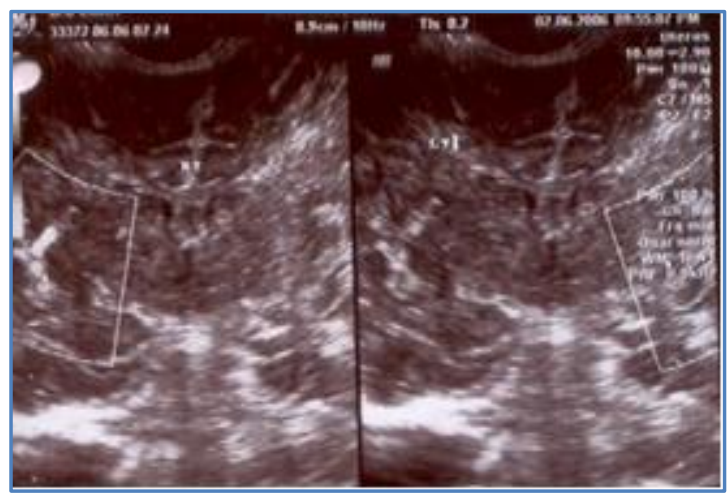

Fig. 2: USG CRANIUM REVEALING RIGHT MCA PULSATION

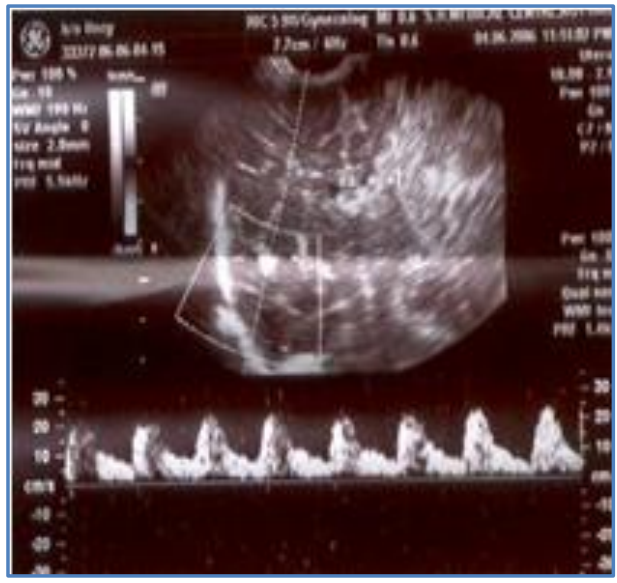

Fig. 3: USG CRANIUM REVEALING RIGHT MCA PULSATION WITH LEFT HEMISPHERE HYPERECHOGENECITY

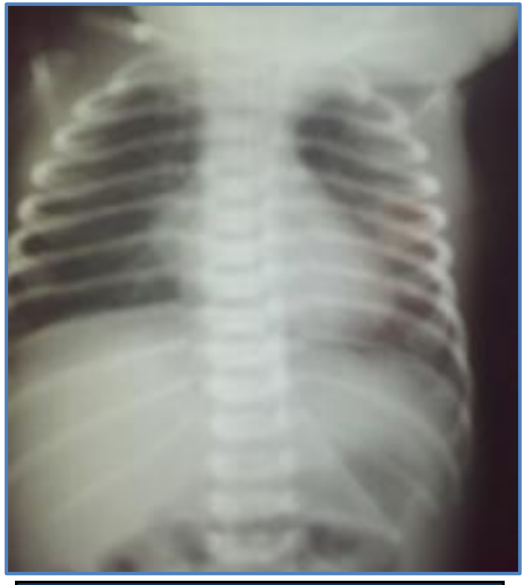

Fig. 4: CHEST XRAY POST PERICARDIALCENTESIS

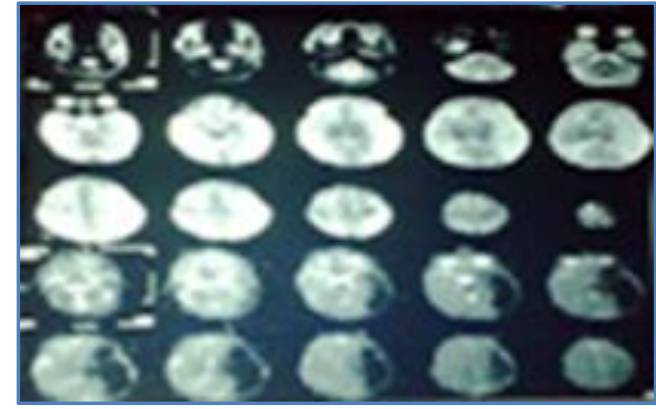

Fig. 5: MRI PHOTOGRAPH OF LEFT HEMISPHERE REVEALING CYSTIC CHANGES 


\section{CASE REPORT}

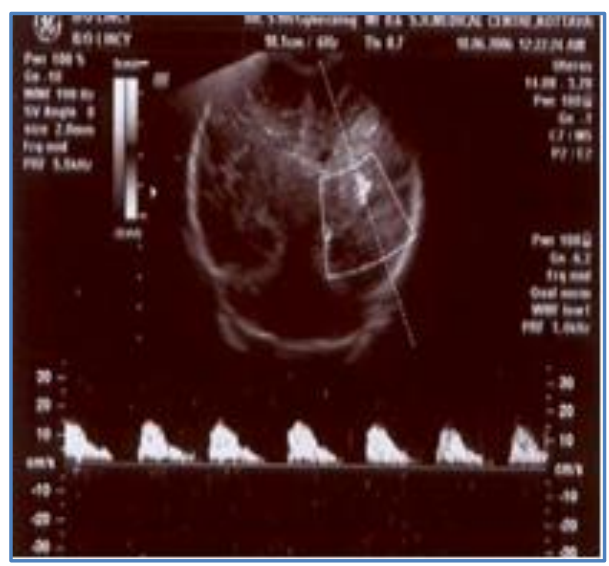

Fig. 6: USG CRANIUM REVEALING LEFT MCA

PULSATION WITH INFARCTION (RECOVERED)

ON EXAMINATION: Full term baby weighing=2.5kg, cry -weak, in severe distress with central cyanosis and blue peripherals. Vitals $=H R=$ clinically difficult to monitor shows $186 / \mathrm{min}$ with low voltage graph. RR=99/min with indrawing SPO2 = 25-30\% BP=not recordable. Chest X-Ray = Pneumopericardium.

Immediately baby was started with headbox 02 10L/min. Prepared for pericardiocentesis, and pneumopericardium was drained by needle aspiration. Within thirty seconds SPO2 improved to $100 \%$ and cyanosis gradually disappeared.

After removing needle serial chest X-rays were taken over several days which revealed gradual decrement in pneumopericardium and SPO2 maintained with in normal limits. Gradually Respiratory distress settled down. In drawing and grunting disappeared, chest $-\mathrm{x}$ rays became completely normal (Fig: 4).

Clinically from first day right half of body movements are decreased, next day it is very evident and third day movements were very less. U/S brain shows Hyperechogenic area on left hemisphere. Doppler examination revealed absent left MCA (middle cerebral artery) pulsations (Fig: 2 \& 3). Immediately air embolism was suspected. To confirm MRI brain was carried out that showed the same pathology. (Fig: 5)

Baby completely recovered from respiratory distress and pneumo pericardium over two to four days. Septic work up was normal and patient discharged with advice about physiotherapy.

Followed up every fifteen days, with US brain. At one and half months the baby had weakness on the right side of the body. The parents were counselled and reassured regarding spontaneous recovery of the weakness. Since parents were very anxious about the baby, they were explained about my personal experience of Piracetam syrup usage, necessary consents were taken before giving medicine.

After starting Piracetam within fifteen days mild collateral pulsations on left hemisphere of brain was noted.

Next fifteen days complete pulsations in left MCA and good improvement in the movements of right half of body (tone, reflex) were noted. Continued the medicine for total 12 months and following all developmental mile stones and hearing test -all were with in normal limit.(Fig: 6) 
DISCUSSION: Air leak syndromes are a group of clinically recognizable disorder produced by alveolar rupture and subsequent escape of air in to the tissue in which air is not normally present.

All the clinical types of air leak syndrome originate in over distended alveoli, which ultimately rupture. Over distention is because of spontaneous vigorous respirations (usually larger team babies) at birth, increased pressure of mechanical ventilator (PEEP, PIP) vigorous Cardio Pulmonary resuscitation, air trapping in the presence of a ball valve mechanism, most of this air leaks occur spontaneously, but incidence increases with ventilator support. ${ }^{2}$

Incidence of these problems depends on severities of disease, gestational age, mode of therapy, experience of personnel handling baby and machines. Most frequent during treatment of RDS and meconium aspiration syndrome. ${ }^{3}$

Pathogenesis: All air leaks are caused by high intra alveolar pressure, because of retention of air or high volume flow. The pressure gradient from the affected alveoli to adjacent tissue spaces will alter, that will cause rupture of the alveolar base that overlies the capillaries. Air escapes through capillary sheaths, which is disrupted, resulting in PIE (Pulmonary Interstitial Emphysema) then air travels through (dissects) perivascular sheaths and migrates towards hilum (called Pneumomediastinum). ${ }^{4}$ Later air enters to the pleural space after dissecting visceral and parietal layer reflection (Pneumothorax).Pneumopericardium occurs if it enters to pericardial reflection where pericardium and visceral layer attaches at Hilum. Sometimes after alveolar rupture air enters through trabecular spaces and enters the visceral pleural space and cause blebs (Pseudo cyst). If air collection increases it ruptures and causes pulmothorax. ${ }^{5}$

If air leaks from hilum to upper portion of body (neck) through vascular sheaths it is called pneumomediastinum. If enters downwards through perivascular sheaths of great vessels and esophagus into retro peritoneal space it is called retro peritoneal emphysema.

Later if posterior peritoneal cavity ruptures it enters to peritoneal cavity causing Pneumo peritoneum. If it dissects into process vaginalis it causes Pneumo scrotum. Sometimes if Alveolar rupture directly into pulmonary vessels it causes Air Embolism.

Another possible pathway involves the dissection of air through the sub adventitial planes of Pulmonary veins thus producing both air embolism and Pneumo pericardium. ${ }^{6}$

Pneumo Mediastinum: Usually occur in small RDS babies or post mature with meconium aspiration babies with vigorous resuscitation at birth or on mechanical ventilation.

Usually asymptomatic,however sometimes causes abnormal clinical signs like tachypnea, bulging sternum, muffled heart sounds, cyanosis according to severity of air collection.

Radio logically [chest X-ray AP view] sometimes is normal or if more air collects it lifts the thymus (bat-wing, angel-wing sign), it is triangle in shape, if more \& more air collects it lifts the thymus and air border below it extends to the lateral side of thorax [Spinnaker sail sign].

The best diagnostic film is lateral chest X-ray. It shows air around heart anteriorly (behind sternum) and superiorly lifting thymus not below [Diaphragmatic border]. This is how we can differentiate between Pneumomediastinum from Pneumopericardium. [In the Pneumopericardium picture air completely surrounds all the border of heart.] ${ }^{7}$

Treatment: Wait\& watch. No aggressive management needed. [Decrease ventilator pressure, PEEP TI (Inspiratory time)] 


\section{CASE REPORT}

Pneumopericardium: Usually associated with other air leak syndrome and occurs in babies on high ventilator settings.

Clinically if mild pneumopericardium is present it may be asymptomatic, if it increases suddenly it causes cyanosis and if it deepens ,it causes decreased heart rate, BP , peripheral pulses not palpable, metabolic acidosis. All these features are because of air compressing the heart and causing decreased stroke volume. On examination Heart sounds are muffled. In ECG, Voltage reduction is evident in $\mathrm{Spo} 2$ monitor graph. ${ }^{8}$

Diagnosis: Chest $\mathrm{X}$ ray A- $\mathrm{P}$ view shows air surrounding the heart borders. In lateral view anterior and inferior border of heart separated by air column.

Treatment: Usually conservative management is enough if there is no cyanosis or severe symptoms, otherwise needle aspiration or catheter placement is necessary for continuous drainage.

\section{Pericardiocentesis:}

Indications: Pneumopericardium/ Pericardial effusion drainage. To obtain pericardial fluids for diagnostic studies

Equipments: Anti septic solution, sterile dress, Gloves22 G, 20 G IV catheter (IV canula), 10ml syringe, 3-way canula, Connecting tubes, under water seal, Multipara monitor with ECG leads.

PROCEDURE: Prepare the area (Xiphoid and Precordium).Prepare the IV cannula with 3- way connector with needle attached. Puncture site $0.5 \mathrm{~cm}$ to the left of and just below the infant's xiphoid.

Advance the needle at $30^{\circ}$ angle aiming towards the mid clavicular line on the left. (FIG. 7) Apply constant pressure while advancing the needle. Once air/ fluid obtain baby's condition is improve/ if left their only connect the underwater seal after securing Take a X ray to confirm.

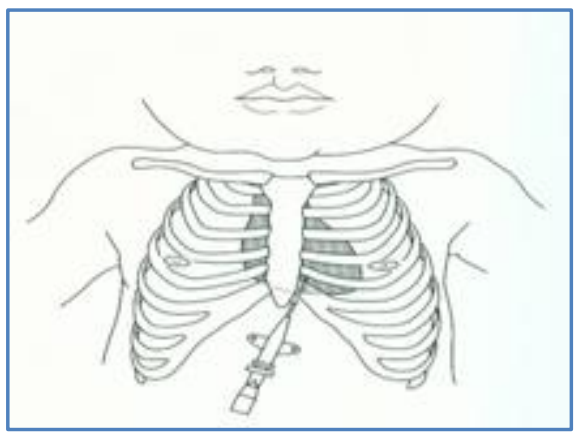

\section{Figure 7: Picture depicts the needle insertion site ${ }^{3}$}

Complications: Puncture of the heart, Pneumothorax, Infection.

CONCLUSION: Pneumopericardium with air embolism together is very rare entity, together occurs only if baby needs vigorous, CPR, high ventilator pressure ${ }^{9}$ But in our case report baby had simple TTN. Probably some mucous or fluid might have acted as ball valve mechanism and it ruptured into perivascular sheaths migrated towards hilum to pericardium at the same time some of pulmonary vessels ruptured and air might have entered into systemic circulation. 
Regarding using of piracetam it is purely personal experience, Improvement in Air embolism is spontaneous.

It could be coincidental or piracetam might have increased microcirculation in the infarcted brain tissue (further studies needed in this regard).

This is first case PNEUMOPERICARDIUM associated with Air embolism in TTN Baby, reported with this complication and without any CPR or on ventilator support, in any available neonatal article, web or journal.

\section{REFERENCES:}

1. Cloherty JP, Eichenwald EC, Stark AR. Pulmonary air leak. Manual of Neonatal Care 6th edn; 2008; 352- 357.

2. Goldsmith JP, Karetkin EH. Pulmonary air leak. Assisted Ventilation of the Neonate 4th edn; 2003; 192-193.

3. Gomella TL. Pulmonary Diseases. Lange clinical manual Neonatology 5th edn; 2007; 524-530.

4. Martin RJ, Fanaroff AA, Walsh MC. Pneumothorax and other air-leak syndromes. Diseases of the Fetus and Infant 8th edn; 2006; 1128-1138.

5. Taeusch HW, Ballard RA, Gleason CA. Principles of respiratory monitoring and therapy. Avery's

6. Diseases of the Newborn 8th edn; 2006; 660-664.

7. McIntosh $\mathrm{N}$ et al. Clinical diagnosis of pneumothorax is late: use of trend data and decision support might allow preclinical detection. Pediatr Res 2002; 48: 408.

8. Mansfield PB et al. Pneumopericardium and pneumomediastinum in infants and children. J Pediatr Surg 1973; 8:691.

9. Bowen FW Jr. Chandra R, Avery BG. Pulmonary interstitial emphysema with gas embolism in hyaline membrane disease. Am J Dis Chld 126:117, 1973.

10. Siegle RL, Eyal FC, Rabinowitz JG. Air embolus following pulmonary interstitial emphysema in hyaline membrane disease. Clin Radiol 27:77, 1976.

\section{AUTHORS:}

1. Dinakara Prithviraj

2. Suresh A.

3. Anna Mariam Paul

\section{PARTICULARS OF CONTRIBUTORS:}

1. Associate Professor, Department of Pediatrics, VIMS \& RC.

2. Assistant Professor, Department of Radiology, VIMS \& RC.

3. Post Graduate, Department of Pediatrics, VIMS \& RC.

\section{NAME ADDRESS EMAIL ID OF THE CORRESPONDING AUTHOR:}

Dr. Dinakara Prithviraj, Vydehi Institute of Medical Sciences and Research Centre, \#82, EPIP Area, White Field, Bangalore - 560066 .

E-mail: drdinakar.nishanth@gmail.com

Date of Submission: 27/03/2014.

Date of Peer Review: 28/03/2014.

Date of Acceptance: 04/04/2014.

Date of Publishing: 09/04/2014. 